\title{
Fibrin Glue Spray as a Simple and Promising Method to Prevent Bleeding after Gastric Endoscopic Submucosal Dissection
}

\author{
Eng Soon Tan ${ }^{a}$ Hua Wang ${ }^{c}$ Guan Way Lua ${ }^{b}$ Feng Liuc Xin Gang Shic \\ Zhao Shen $\mathrm{Li}^{\mathrm{c}}$
}

Department of Gastroenterology ${ }^{\mathrm{a} H o s p i t a l ~ K u a l a ~ L u m p u r, ~ K u a l a ~ L u m p u r, ~ a n d ~}{ }^{\mathrm{b}}$ Raja Perempuan 2 Hospital, Kelantan, Malaysia; ' Department of Gastroenterology, Changhai Hospital, Second Military Medical University, Shanghai, China

\section{Key Words}

Endoscopic submucosal dissection · Delayed bleeding ·

Fibrin glue · Early gastric cancer

\begin{abstract}
Aim: This study was conducted to evaluate the effectiveness of fibrin glue (FG) in preventing delayed bleeding after gastric endoscopic submucosal dissection (ESD). Methods: From 2011 to 2014, 423 patients undergoing gastric ESDs were studied retrospectively. After excluding 26 patients, 397 were enrolled. The post-ESD wounds were treated with only coagrasper/clips before April 2013. After that, additional FG spray was utilized for wound closure. The post-ESD bleeding rates were compared between the FG group (patients with postoperative use of $F G$ ) and the non-FG group (patients without the use of FG). Results: A total of 397 lesions were successfully resected from 397 patients. The FG group significantly had more risk factors predisposing to delayed bleeding, such as advanced age, larger specimen size, more cancerous lesions and longer operation time. There was no significant difference in gender, comorbidity, lesion locations, numbers of coagrasper and hemoclips used between the 2 groups. The total rate of delayed bleeding was $4.53 \%$ (18/397). There were 18 cases of delayed bleeding $(5.98 \%)$ in the non-FG group and none in the FG group ( $p=$ 0.03). Univariate analysis showed that FG reduced the risk of
\end{abstract}

\begin{tabular}{|c|c|}
\hline KARGER & (C) 2016 The Author(s) \\
\hline & $0253-4886 / 16 / 0336-0455 \$ 39.50 / 0$ \\
\hline www.karger.com/dsu & $\begin{array}{l}\text { This article is licensed under the Creative Commons Attribution- } \\
\text { NonCommercial-NoDerivatives } 4.0 \text { International License (CC BY- } \\
\text { NC-ND) (http://www.karger.com/Services/OpenAccessLicense). } \\
\text { Usage and distribution for commercial purposes as well as any dis- } \\
\text { tribution of modified material reguires written permission. }\end{array}$ \\
\hline
\end{tabular}

delayed bleeding significantly $(p=0.03)$. Conclusion: $F G$ was simple and effective in preventing delayed bleeding after gastric ESDs.

(c) 2016 The Author(s)

Published by S. Karger AG, Basel 
endoscopy [12] have been used to reduce the risk of delayed bleeding. Recently, there was also a report about the use of medical adhesives to reduce delayed bleeding after gastric ESD [13].

A few pilot studies have been performed to evaluate the prevention of delayed perforations, esophageal strictures and delayed bleeding after ESD by using polyglycolic acid (PGA) sheets plus fibrin glue (FG) to cover ESD wounds [14-17]. However, the method of placing PGA sheets on mucosal defects and fixation with FG through an endoscope is technically demanding and time consuming.

In the past, FG has been used extensively during surgery for tissue adhesion, suture support, and hemostasis. Spraying of FG onto ESD wounds through an endoscope is easy. Moreover, to our knowledge, there have been no reports concerning the use of FG alone as a hemostatic technique for ESD. The aim of our study was to investigate the efficacy of porcine derived FG spray in preventing delayed bleeding after gastric ESD.

\section{Methods}

\section{Patients}

This was a nonrandomized retrospective cohort study. We collected data from all consecutive patients who underwent gastric ESD from January 2011 to August 2014 at Changhai Hospital, Second Military Medical University, Shanghai. Inclusion criteria were EGC or lesions that met the expanded criteria for endoscopic treatment [18]; and gastric high grade intraepithelial neoplasia, and gastric adenomas. Exclusion criteria included failure to obtain informed consent, severe cardiopulmonary diseases (American Society of Anesthesiologists class III and above), severe uncorrectable coagulopathy (pre-ESD platelet count $<70,000$ per microliter), known cases of severe allergies or anaphylactic reaction toward porcine products, severe intra operative bleeding or perforation not amenable to endoscopic treatment, or artificial wounds that were closed by mechanical means (such as endoloops). The post-ESD wounds were treated with coagraspers or clips in our center prior to April 2013. After that, ESD wounds were treated by spraying FG. All ESDs were performed by 2 local experts at our center, each with over 100 cases of ESD per year over the preceding 5 years. Patients taking aspirin or antiplatelet agents were asked to stop the medications at least 5 days prior to ESD procedure. Medication was resumed on day 7 after the ESD. Warfarin was also discontinued before ESD and heparin was initiated as bridging therapy if needed. Prothrombin ratio-international normalized ratio (PT-INR) would be checked 3-4 days later after stopping the warfarin. We would proceed with ESD if PT-INR $\leq 1.5$.

The patients were divided into 2 groups: those who were given FG spray (FG group) and those without (non-FG group). All subjects submitted written forms of informed consent for the application of FG in addition to giving consent for ESD according to normal clinical practice. This study was approved by the Changhai Hospital Ethics Committee.

\section{Definition of Delayed Bleeding}

Delayed bleeding was defined as hematemesis or melena that required endoscopic hemostasis and decreased in hemoglobin by $\geq 2 \mathrm{~g} / \mathrm{dl}$, occurring between days 1 and 30 after ESD.

\section{Instruments and Adhesive}

Olympus GIF-Q260J electronic gastroscopes with a transparent cap attached were used for ESD procedure. Olympus NM-4L-1 injection needles with a sterilized solution of glycerol (10\% glycerol and fructose 5\%, Huadong Pharmaceutical, Shanghai, China) premixed with indigo carmine, and $2 \mathrm{ml}$ of 1:10,000 epinephrine were used for submucosal injection. IT-2 knife (KD-611L; Olympus Optical, Tokyo, Japan) and Dual Knife (KD-611L; Olympus) were used independently or in combination for marking and resection. Hemostatic clips (Olympus), coagrasper (Olympus) and ERBE ICC-200 high-frequency electric cutting device were also utilized. All ESDs were performed under carbon dioxide insufflation.

The porcine FG (YueLingJiao ${ }^{\circledR}, 2.5 \mathrm{ml}$, Hangzhou PuJi Medical Tech, Hangzhou, China; China Food and Drug Administration (FDA) number: S20120009, 2012-02-10) is a spray-type adhesive used primarily for surgical wound sealant. Its main ingredient consists of 2 components: (i) fibrinogen, factor XIII and phosphate buffer and (ii) prothrombin and calcium chloride $\left(\mathrm{CaCl}_{2}\right)$ solution. After mixing the 2 components, a gel is formed within $5-10 \mathrm{~s}$, producing the desired hemostatic closure adhesive effect. We usually added Indigo carmine, $0.3 \mathrm{ml}$, to the glue mixture for visualization to ensure adequate coverage of the entire wound area.

\section{ESD Procedure}

All patients underwent ESD under general anesthesia with intubation or deep sedation with intravenous propofol. (1) During endoscopy, the lesions were identified under white light and subsequently narrow band image with indigo carmine staining; (2) a dual knife was used to mark at about $5 \mathrm{~mm}$ lateral to the margin of lesion; (3) premixed solution (as mentioned above) was injected into the submucosa layer to elevate the lesions; (4) a dual knife was used to incise the mucosa outside the marked points at the lesion edges; (5) the dual knife and IT-2 knife were used to make a circular incision on the lesion edge along the marker and to dissect the submucosa, layer by layer, until the lesion was removed. In some cases, when the lesion was almost completely removed, a polypectomy snare was used to assist the lesion removal; and (6) after resection, small visible blood vessels were coagulated with coagrasper or clipped using hemostatic clips [10]. Any visible perforations at the wound surface were closed with hemostatic clips. In addition, FG was sprayed onto the wound surface using a special spray catheter in FG group patients. This tube had 2 channels. We simultaneously sprayed fibrinogen, factor XIII and phosphate buffer through one channel, with prothrombin and calcium chloride activator solution through the other channel (fig. 1). Once the 2 ingredients were exposed to each other, an adhesive gel-like material would form immediately, covering the wound surface.

\section{Post-ESD Monitoring and Follow-Ups}

Patients were observed in the hospital for at least $48 \mathrm{~h}$ after the procedure with $6 \mathrm{~h}$ vital signs monitoring. Patients were kept nil by mouth, and given intravenous fluid for $24 \mathrm{~h}$. Clear fluids and then soft diets were introduced gradually. Pantoprazole were given 

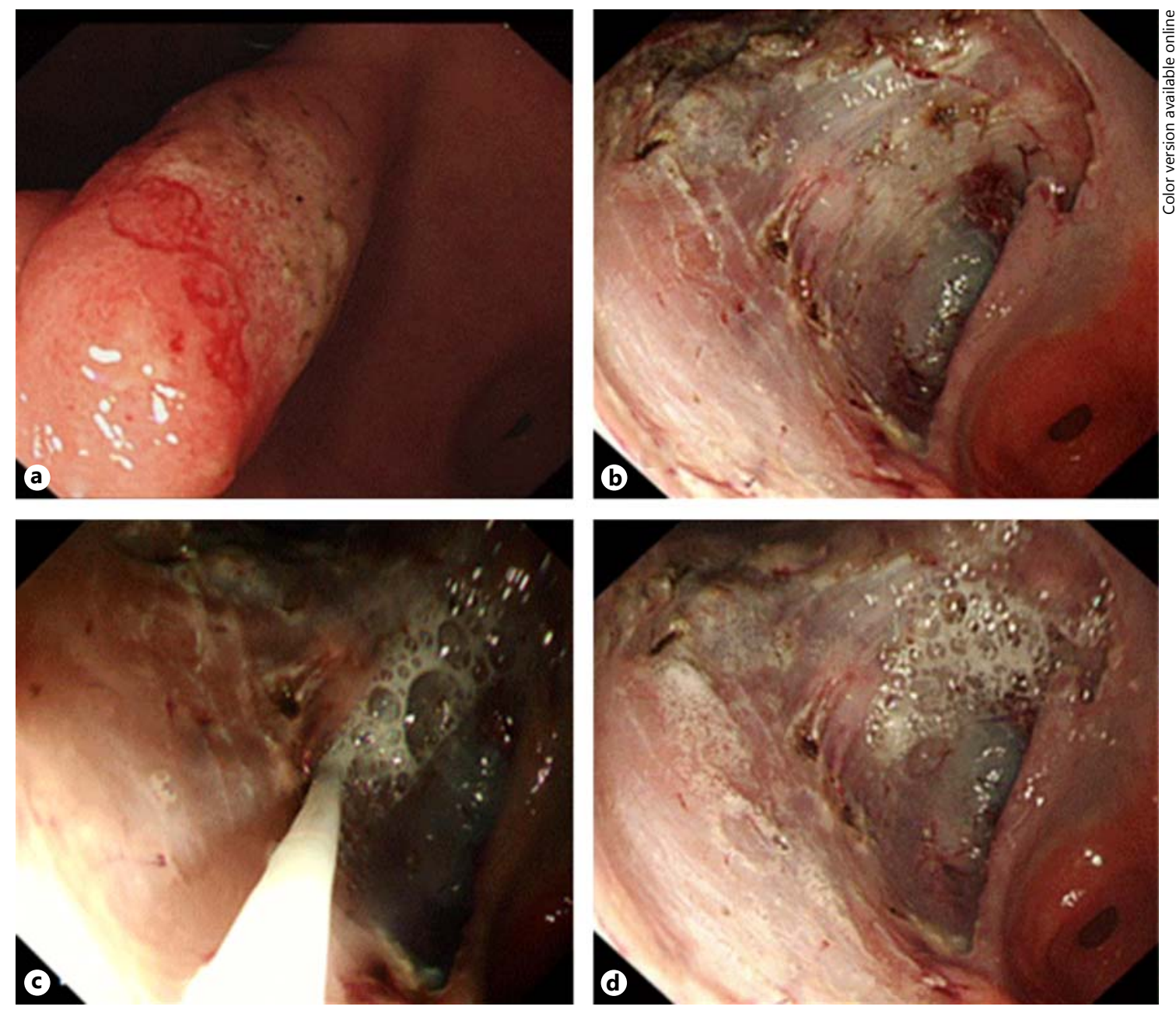

Fig. 1. Gastric wound, from one of the patients, which was treated with FG after ESD. a An EGC $>3 \mathrm{~cm}$ located at antral wall of gastric angularis. b Large mucosal defect after ESD. c Application of FG through a special tube. d The appearance of wound after completion of FG application.

intravenously ( $40 \mathrm{mg}$ twice a day) for the first $48 \mathrm{~h}$. Oral pantoprazole (40 mg daily) was prescribed for 1 month after discharge. Endoscopy was repeated at 3, 6, and 12 months after ESD.

\section{Statistics}

SPSS 10.0 statistical software was used for analysis and the statistical significance level $\alpha$ was set at 0.05 . Categorical data were analyzed using the $\chi^{2}$ method. A multivariate analysis was not performed because the number of some events (the number of bleeding case in FG group was 0 ) was too small to analyze.

\section{Results}

Four hundred and twenty-three consecutive patients underwent gastric ESD in our center. A total of 26 patients were excluded: 5 patients underwent surgery $(3$ had severe intraoperative hemorrhage that failed hemostasis and 2 had perforations that were not amendable to endoscopic therapy). Another 21 patients were excluded because the wound surfaces were closed using metallic clips and endoloops. The remaining 397 patients were enrolled in the study. There were 217 males (54.7\%) and $180 \mathrm{fe-}$ males (45.3\%) with a mean age of $55.47 \pm 12.23 \mathrm{SD}$. The clinical characteristics of 397 gastric lesions in patients with gastric neoplasms are shown in table 1.

From the analysis of the clinical characteristic of both groups of patients, there was no statistically significant difference in gender, location of lesions, comorbidity, use of anticoagulant or antiplatelet, and numbers of coagrasper and hemoclips used. There were no subjects with clinically significant renal impairment (defined as chron- 
Table 1. Clinical characteristics of gastric neoplasms in patients and outcome of ESD procedure

\begin{tabular}{|c|c|c|c|c|}
\hline & $\begin{array}{l}\text { All patients } \\
(\mathrm{n}=397)\end{array}$ & $\begin{array}{l}\text { FG group } \\
(\mathrm{n}=96)\end{array}$ & $\begin{array}{l}\text { Non-FG group } \\
(\mathrm{n}=301)\end{array}$ & $\mathrm{p}$ value \\
\hline Gender (female/male) & $180 / 217$ & $39 / 57$ & $141 / 160$ & 0.287 \\
\hline Age $(<65 / \geq 65)$, years & $301 / 96$ & $64 / 32$ & $237 / 64$ & 0.016 \\
\hline \multicolumn{5}{|l|}{ Comorbidity, n (\%) } \\
\hline Liver cirrhosis & $9(2.3)$ & $3(3.1)$ & $6(2.0)$ & 0.378 \\
\hline Diabetes mellitus & $30(7.6)$ & $8(8.3)$ & $22(7.3)$ & 0.262 \\
\hline Ischemic heart disease & $12(3.0)$ & $3(3.1)$ & $9(3.0)$ & 0.331 \\
\hline Hypertension & $170(42.8)$ & $62(64.6)$ & $108(35.9)$ & 0.098 \\
\hline Anticoagulant or antiplatelet used & $20(5.0)$ & $5(5.2)$ & $15(5.0)$ & 0.225 \\
\hline \multicolumn{5}{|l|}{ Location of tumor in the stomach, $\mathrm{n}(\%)$} \\
\hline Upper & $146(36.8)$ & $44(45.8)$ & $102(33.9)$ & 0.123 \\
\hline Middle & $101(25.4)$ & $15(15.6)$ & $86(28.6)$ & \\
\hline Lower & $150(37.8)$ & $37(38.5)$ & $113(37.5)$ & \\
\hline Use of coagrasper (yes/non) & $288 / 109$ & $76 / 20$ & $212 / 89$ & 0.095 \\
\hline Use of hemoclips (yes/non) & $365 / 32$ & $85 / 11$ & $280 / 21$ & 0.16 \\
\hline Diameter of lesions $(<40 / \geq 40 \mathrm{~mm})$ & $274 / 123$ & $54 / 42$ & $220 / 81$ & $<0.001$ \\
\hline Cancerous lesion (yes/non) & $123 / 274$ & $42 / 54$ & $87 / 214$ & 0.017 \\
\hline Procedure time, min, mean $\pm \mathrm{SD}$ & $54.57 \pm 29.64$ & $66.13 \pm 35.16$ & $50.88 \pm 26.68$ & $<0.001$ \\
\hline Delayed bleeding, n (\%) & $18(4.5)$ & 0 & $18(5.9)$ & 0.03 \\
\hline
\end{tabular}

ic kidney disease stage 3 and above or glomerular filtration rate below $60 \mathrm{ml} / \mathrm{min} / 1.73 \mathrm{~m}^{2}$ ). However, the patients in the FG group tended to be older as compared to the non-FG group ( $p=0.016)$. In the FG group, there were significantly more cancerous lesions resected $(\mathrm{p}=$ 0.017 ), and the lesions were significantly larger (diameter $>40 \mathrm{~mm}, \mathrm{p}<0.001$ ) as compared to those in the non-FG group. The total ESD time was also significantly longer in the FG group $(66.13 \pm 35.16 \mathrm{~min}, \mathrm{p}<0.001)$, as compared to the non-FG group $(50.88 \pm 26.68 \mathrm{~min})$. The total rate of delayed bleeding was $4.53 \%$ (18/397) in both groups. There were 18 cases of delayed bleeding that occurred $(5.98 \%)$ in the non-FG group, while there were none in the FG group. There was a significant difference in postESD bleeding rate between the 2 groups ( $p=0.03$; table 1). In our study, there were no reported cases of delayed perforation in both groups.

Among all 18 patients with delayed bleeding, bleeding in $15(83.3 \%)$ occurred within $24 \mathrm{~h}$ after ESD. For 2 (11.1\%) it occurred at day 3 after ESD, while for $1(5.6 \%)$ it occurred at day 7 after ESD. Bleeding was resolved with endoscopic treatment involving the use of adrenaline injection, heater probe, and hemoclip application. Seven patients $(38.9 \%)$ required blood transfusions. None required surgery and there was no mortality reported.

We also performed univariate analysis to compare both bleeding and non-bleeding groups. The lack of use of FG was significantly related to delayed bleeding ( $\mathrm{p}=$
0.03 ). Large lesion (diameter $>40 \mathrm{~mm}$ ) was significantly related to delayed bleeding $(\mathrm{p}=0.002)$. Additionally, gastric cancerous lesions were significantly more likely to bleed than gastric non-cancerous lesions ( $p=0.027$ ). There was no significant association between age, gender, location of lesions, comorbidity, anticoagulant or antiplatelet, and numbers of coagrasper and hemoclips used (table 2).

\section{Discussion}

In our study, the rate of delayed bleeding was $4.53 \%$, and this fell within the range quoted in a previous study [5-9]. In an effort to minimize ESD-related bleeding, studies have evaluated risk factors for bleeding after ESD. Intra-procedural bleeding develops more commonly with lesions in the upper third of the stomach because of abundant distribution of vessels in the submucosa [19]. In contrast to intra-procedural bleeding, post-procedural bleeding is observed more frequently in lesions in the middle or lower third of the stomach [20, $21]$. Large specimen size and long operation time are also well-known risk factors for delayed bleeding $[6,8$, 20]. In our study, those in the FG group had more risk factors predisposed to delayed bleeding, such as advanced age, larger specimen size, more cancerous lesions and longer operation time. Although we did not 
Table 2. Univariate analysis of clinical characteristics associated with delayed bleeding

\begin{tabular}{lccc}
\hline & $\begin{array}{l}\text { Bleeding group } \\
(\mathrm{n}=18)\end{array}$ & $\begin{array}{l}\text { Non-bleeding group } \\
(\mathrm{n}=379)\end{array}$ & $\mathrm{p}$ value \\
\hline Gender (female/male) & $6 / 12$ & $174 / 205$ & 0.295 \\
Age $(<65 / \geq 65)$, years & $13 / 5$ & $288 / 91$ & 0.934 \\
Comorbidity, $(\%)$ & & & 0.275 \\
$\quad$ Liver cirrhosis & $1(5.5)$ & $8(2.1)$ & 0.786 \\
$\quad$ Diabetes mellitus & $2(11.1)$ & $28(7.4)$ & 0.335 \\
$\quad$ Hypertension & $6(33.3)$ & $164(43.3)$ & 0.890 \\
$\quad$ Ischemic heart disease & $1(5.5)$ & $11(2.9)$ & 0.08 \\
$\quad$ Anticoagulant or antiplatelet used & $1(5.5)$ & $19(5.0)$ & 0.794 \\
Location (upper/middle/lower) & $6 / 6 / 6$ & $96 / 18 / 283$ & 0.03 \\
Use of FG (yes/non) & $16 / 2$ & $272 / 107$ & 0.187 \\
Use of coagrasper (yes/non) & $16 / 2$ & $349 / 30$ & 1 \\
Use of hemoclip (yes/non) & $6 / 12$ & $260 / 119$ & 0.002 \\
Diameter of lesions (<40/ $\geq 40$ mm) & $10 / 8$ & $112 / 267$ & 0.027 \\
Cancer (yes/non) & $64.78 \pm 26.90$ & $54.08 \pm 29.71$ & 0.135 \\
Procedure time, min, mean $\pm \mathrm{SD}$ & & &
\end{tabular}

show a significant relationship between location of lesion and bleeding, our study agreed with Okada et al. [20] that the diameter of lesions ( $\geq 40 \mathrm{~mm}$ ) was significantly related to delayed bleeding.

Takizawa et al. [10] reported that the routine use of coagulation reduced delayed bleeding. However, our study did not find any significant relationship between these 2 factors. While the frequency of postoperative bleeding has been gradually decreased due to the development of post-ESD coagulation therapy and use of PPIs, it still remains one of the primary concerns. Second-look endoscopy after hemostasis for peptic ulcer bleeding has been reported to be useful for the prevention of re-bleeding. However, several randomized control trials suggested that the performance of second-look endoscopy within a few days after ESD did not reduce the incidence of postoperative bleeding, and was considered to be unnecessary [22]. Therefore, there are a few effective methods to prevent delayed ESD bleeding currently.

Zhang et al. [13] suggested that the use of medical adhesive glue, in which the primary ingredient was cyanoacrylate, would reduce the risk of delayed bleeding postESD. However, that study involved a significant number of non-gastric lesions ( $36 \%$ of all lesions). This heterogeneous group of patients made the interpretation of results difficult. We preferred the use of FG as an additional prophylaxis for delayed bleeding only in gastric ESD. In our wopinion, artificially created gastric ulcers are exposed to multiple factors in the stomach that may theoretically increase the risk of delayed bleeding. These include active peristalsis, acidic environment and bile reflux that may impair the healing of gastric ulcers.

In our center, porcine-derived FG was selected due to its advantages over medical glue (cyanoacrylate). They would minimize the risk of instrument damage, especially occlusion of the working channel and glue adherence to the tip of the endoscope. Porcine-derived FG would omit the risk of viral transmission such as human parvovirus B19, which was reported in Japan with the use of plasma-derived sealant [23]. However, FG formulations using thrombin derived from animal sources do carry a small risk of adverse immunological response. There have been reports of patients who developed antibodies against bovine thrombin leading to a strong immunological response [24]. In our cohort of patients, this did not occur. However, we did not recommend its use in patients with known history of severe allergies.

Fibrin sealant is a 2-component material consisting of fibrinogen and thrombin. In the presence of small amounts of calcium and factor XIII, the thrombin converts fibrinogen into insoluble fibrin, the final stable form of the agent. Once it is exposed to potentially leaking blood vessels, FG may have a hemostatic effect by blocking holes in the vessel and prevent subsequent bleeding. Fibrin sealant has been used for over a century and has a good safety profile. Fibrin sealant is the only commercially available FDA-approved material for clinical use in all 3 of these groupings: hemostats, sealants, and adhesives. More recently, Tsuji et al. [17] reported that endoscopic tissue shielding method with PGA sheets and FG 
appeared to be promising in the prevention of gastric post-ESD bleeding. In fact, FG alone maybe effective enough to prevent post-ESD bleeding without the use of PGA sheets. Furthermore, it was faster and less technically demanding as compared to PGA sheets, which had a reported mean time of application of $12.8 \mathrm{~min}$. In our study, there were no cases of delayed bleeding in the FG group, while there were 18 cases of delayed bleeding in the non-FG group (5.98\%), and this difference was statistically significant. Furthermore, there were significantly larger lesions and older patients in the FG group, which would have increased the risk of delayed bleeding after gastric ESD [20] in that group.

Beside hemostasis, FG will form a 'clot' by mimicking the terminal phase of the physiologic clotting cascade, producing fibrin monomers that subsequently assemble into a stronger cross-linked fibrin polymer [25]. So FG acts as a protective biomembrane over the gastric artificial ulcer, which is impermeable to acidic gastric fluid. FG will be fully absorbed within 2 weeks of application in the surgical field [26]. Further exploration is needed to determine the exact time of absorption of FG in post-ESD wounds. FG has been shown to exert beneficial effects on ulcer healing by recruiting proliferating cells in the ulcer margin and enhancing the density of microvessels [27]. We speculated that FG may also promote the healing of artificial ulcer induced by ESD. This may contribute to the prevention of delayed bleeding after ESD.

This study had some limitations including the fact that it was a nonrandomized retrospective study in a single center. A randomized controlled study involving a larger number of patients is more desirable to demonstrate the efficacy of FG.

\section{Conclusion}

In conclusion, based on our retrospective analysis, FG spray post-gastric ESD was a simple and promising method for reducing the risk of delayed bleeding.

\section{Statement of Ethics}

Ethics Committee approval was obtained.

\section{Disclosure Statement}

Authors declare no conflict of interests for this article.

\section{References}

1 Kim KO, Kim SJ, Kim TH, et al: Do you have what it takes for challenging endoscopic submucosal dissection cases? World J Gastroenterol 2011;17:3580-3584.

2 Gotoda T, Yamamoto H, Soetikno RM: Endoscopic submucosal dissection of early gastric cancer. J Gastroenterol 2006;41:929-942.

3 Oka S, Tanaka S, Kaneko I, et al: Advantage of endoscopic submucosal dissection compared with EMR for early gastric cancer. Gastrointest Endosc 2006;64:877-883.

4 Oda I, Saito D, Tada M, et al: A multicenter retrospective study of endoscopic resection for early gastric cancer. Gastric Cancer 2006; 9:262-270.

5 Lim SM, Park JC, Lee H, et al: Impact of cumulative time on the clinical outcomes of endoscopic submucosal dissection in gastric neoplasm. Surg Endosc 2013;27:1397-1403.

6 Nakamura M, Nishikawa J, Hamabe K, et al: Risk factors for delayed bleeding from endoscopic submucosal dissection of gastric neoplasms. Scand J Gastroenterol 2012;47:11081114.

7 Goto O, Fujishiro M, Oda I, et al: A multicenter survey of the management after gastric endoscopic submucosal dissection related to postoperative bleeding. Dig Dis Sci 2012;57:435-439.
8 Higashiyama M, Oka S, Tanaka S, et al: Risk factors for bleeding after endoscopic submucosal dissection of gastric epithelial neoplasm. Dig Endosc 2011;23:290-295.

9 Oda I, Suzuki H, Nonaka S, et al: Complications of gastric endoscopic submucosal dissection. Dig Endosc 2013;25(suppl 1):71-78.

10 Takizawa K, Oda I, Gotoda T, et al: Routine coagulation of visible vessels may prevent delayed bleeding after endoscopic submucosal dissection - an analysis of risk factors. Endoscopy 2008;40:179-183.

11 Tomita T, Kim Y, Yamasaki T, et al: Prospective randomized controlled trial to compare the effects of omeprazole and famotidine in preventing delayed bleeding and promoting ulcer healing after endoscopic submucosal dissection. J Gastroenterol Hepatol 2012;27: 1441-1446.

12 Goto O, Fujishiro M, Kodashima S, et al: A second-look endoscopy after endoscopic submucosal dissection for gastric epithelial neoplasm may be unnecessary: a retrospective analysis of postendoscopic submucosal dissection bleeding. Gastrointest Endosc 2010; 71:241-248.

13 Zhang Y, Chen Y, Qu CY, et al: Effects of medical adhesives in prevention of complications after endoscopic submucosal dissection. World J Gastroenterol 2013;19:2704-2708.

14 Sakaguchi Y, Tsuji Y, Ono S, et al: Polyglycolic acid sheets with fibrin glue can prevent esophageal stricture after endoscopic submucosal dissection. Endoscopy 2015;47:336-340.

15 Takimoto K, Imai Y, Matsuyama K: Endoscopic tissue shielding method with polyglycolic acid sheets and fibrin glue to prevent delayed perforation after duodenal endoscopic submucosal dissection. Dig Endosc 2014; 26(suppl 2):46-49.

16 Tsuji Y, Ohata K, Gunji T, et al: Endoscopic tissue shielding method with polyglycolic acid sheets and fibrin glue to cover wounds after colorectal endoscopic submucosal dissection (with video). Gastrointest Endosc 2014;79: 151-155.

17 Tsuji Y, Fujishiro M, Kodashima S, et al: Polyglycolic acid sheets and fibrin glue decrease the risk of bleeding after endoscopic submucosal dissection of gastric neoplasms (with video). Gastrointest Endosc 2015;81:906-912.

18 Gotoda T, Yanagisawa A, Sasako M, et al: Incidence of lymph node metastasis from early gastric cancer: estimation with a large number of cases at two large centers. Gastric Cancer 2000;3:219-225. 
19 Muraki Y, Enomoto S, Iguchi M, et al: Management of bleeding and artificial gastric ulcers associated with endoscopic submucosal dissection. World J Gastrointest Endosc 2012; 4:1-8.

20 Okada K, Yamamoto Y, Kasuga A, et al: Risk factors for delayed bleeding after endoscopic submucosal dissection for gastric neoplasm. Surg Endosc 2011;25:98-107.

21 Tsuji Y, Ohata K, Ito T, et al: Risk factors for bleeding after endoscopic submucosal dissection for gastric lesions. World J Gastroenterol 2010;16:2913-2917.
22 Kim JS, Chung MW, Chung CY, et al: The need for second-look endoscopy to prevent delayed bleeding after endoscopic submucosal dissection for gastric neoplasms: a prospective randomized trial. Gut Liver 2014;8: 480-486.

23 Kawamura M, Sawafuji M, Watanabe M, et al: Frequency of transmission of human parvovirus B19 infection by fibrin sealant used during thoracic surgery. Ann Thorac Surg 2002; 73:1098-1100.

24 Bänninger $\mathrm{H}$, Hardegger $\mathrm{T}$, Tobler $\mathrm{A}$, et al: Fibrin glue in surgery: frequent development of inhibitors of bovine thrombin and human factor V. Br J Haematol 1993;85:528-532.
25 ASGE Technology Committee, Bhat YM, Banerjee $\mathrm{S}$, et al: Tissue adhesives: cyanoacrylate glue and fibrin sealant. Gastrointest Endosc 2013;78:209-215.

26 Pescatore P, Verbeke C, Härle M, et al: Fibrin sealing in peptic ulcer bleeding: the fate of the clot. Endoscopy 1998;30:519-523.

27 Becker JC, Beckbauer M, Domschke W, et al: Fibrin glue, healing of gastric mucosal injury, and expression of growth factors: results from a human in vivo study. Gastrointest Endosc 2005;61:560-567. 